\title{
A case report of visceral leishmaniasis and malaria co-infection with pancytopenia and splenomegaly - a diagnostic challenge
}

\author{
Pragya Gautam Ghimire ${ }^{1 *} \mathbb{D}$, Prasanna Ghimire ${ }^{2}$, Jyoti Adhikari ${ }^{3}$ and Anurag Chapagain ${ }^{4}$
}

\begin{abstract}
Background: Leishmaniasis and malaria are tropical diseases with more than half of the world population at risk of infection resulting in significant morbidity and mortality. Co-infection of Leishmaniasis and malaria pose a great challenge in the diagnosis as well as overall management.

Case presentation: In this case report, we present a rare case of a 5 years old child hailing from non-endemic region of Nepal with history of fever for a period of 3 months who was diagnosed as co-infection of malaria due to Plasmodium vivax and visceral Leishmaniasis with pancytopenia that subsequently improved after a course of treatment.

Conclusions: A high index of suspicion for a possibility of co-infection with Leishmaniasis and malaria should be borne in mind when an individual hailing from or having history of travel to endemic countries presents with prolonged fever.
\end{abstract}

Keywords: Leishmaniasis, Malaria, Co-infection, P.vivax

\section{Background}

Leishmaniasis and malaria are tropical diseases with endemecity noted in various regions of the world. Both the diseases are of public health problems resulting in significant morbidity and mortality even with treatment. An early diagnosis is important in management of cases [1]. Although few studies have demonstrated co - infection of visceral Leishmaniasis and malaria in certain African and Middle East populations, such association noted in South Asia is limited [2]. We present a case of visceral Leishmaniasis and Malaria co-infection complicated with pancytopenia and fever in a child hailing from Jajarkot District of Karnali Region, a non-endemic region of Malaria posing a diagnostic challenge. To our knowledge, no such cases have been reported from Nepal.

\section{Case presentation}

A-5 year- old child hailing from a rural hilly region of Nepal presented with history of on and off high grade

\footnotetext{
* Correspondence: drpragya@gmail.com

${ }^{1}$ Department of Pathology, Nepalgunj Medical College and Teaching

Hospital, Kohalpur, Banke 21904, Nepal

Full list of author information is available at the end of the article
}

fever associated with chills and rigor, abdominal pain and constipation for a duration of 3 months. Patient was treated locally for his symptoms that did not resolve which was then referred to our hospital for further management. On physical examination, patient was febrile, hepatosplenomegaly was noted (Fig. 1). An ultrasound examination confirmed hepatosplenomegaly. Laboratory investigation demonstrated pancytopenia with hemoglobin $-7.2 \mathrm{~g} / \mathrm{dl}$, RBC $2.94 \times 10^{12 /} \mathrm{L}$, WBC $2.90 \times$ $10^{9} / \mathrm{L}$, Platelet count- $63 \times 10^{9} / \mathrm{L}$. On peripheral blood smear, schizont of $P$. vivax malaria as well as intracellular Leishmania-Donovan (LD) bodies were noted (Figs. 2 and 3). rK 39 immunochromatographic and malaria rapid diagnostic test (RDT) for $P$. vivax were positive. Child was treated with chloroquine phosphate with first and second dose of $10 \mathrm{mg}$ base/ $\mathrm{kg} /$ at $24 \mathrm{~h}$ interval followed by third dose of $5 \mathrm{mg}$ base/ $\mathrm{kg}$ after $24 \mathrm{~h}$. Child was referred to nearby government hospital for a free supply of single dose of liposomal amphotericin B (10 $\mathrm{mg} / \mathrm{kg}$ ) as infusion. Child was also started on Primaquine phosphate $(0.5 \mathrm{mg} / \mathrm{kg} /$ day $)$ for 15 days. Patient had significantly improved clinically and a blood film on follow up demonstrated parasite clearance. 




Fig. 1 Photograph of the patient demonstrating hepatosplenomegaly

\section{Discussion and conclusions}

Malaria as a tropical disease is of significant public health problem worldwide with an estimated 3.2 billion people at risk and with ongoing malaria transmission in 91 countries. In Nepal, southern plains which has border with India are endemic for malaria with majority of the

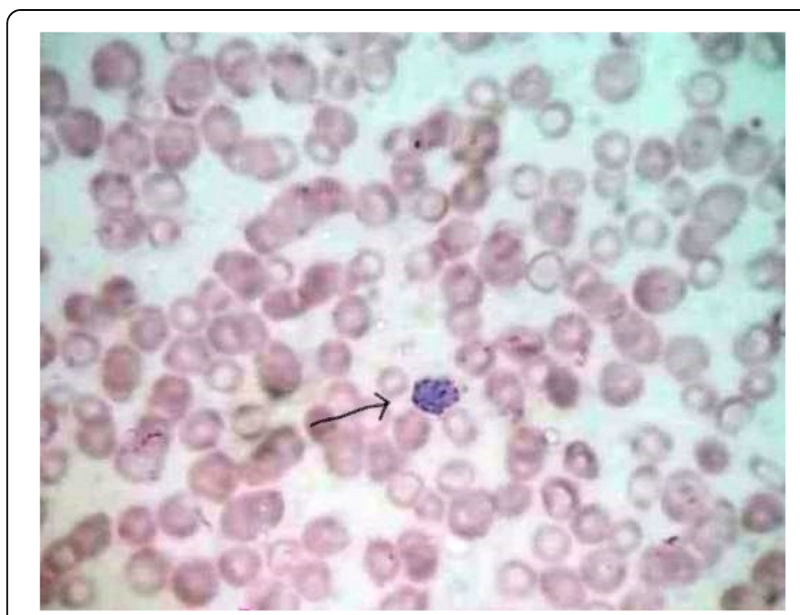

Fig. 2 Photomicrograph showing schizont of $P$. vivax malaria in thicker portion of the film. (Wright stain, X 100)

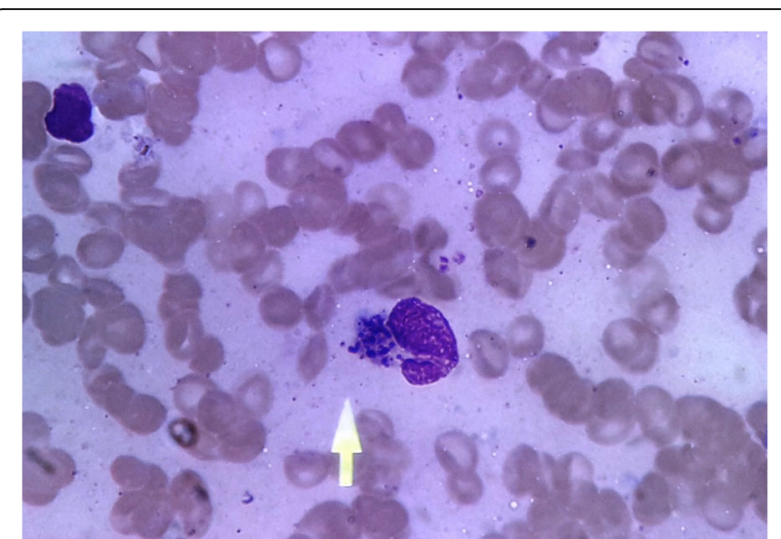

Fig. 3 Leishmania Donovani (LD bodies inside a monocyte. (Wright stain, X 100)

cases due to Plasmodium vivax [3]. Although, there has been a significant improvement towards achieving malaria elimination in Nepal, still significant number of cases is annually recognized. A major problem which is noted is the significant co-infection of malaria with other diseases that has not been addressed and programmes not tailored to curtail such cases [4].

Another tropical disease of much concern in South Asia with significant morbidity and mortality is Leishmaniasis. The southern belt (Terai region) of Nepal is also endemic for visceral Leishmaniasis. Major control programmes are concentrated in these regions. However, there has been a geographical variation in cases of Leishmaniasis recently. Few cases are even noted in Hilly regions of Nepal [1]. Moreover, studies have demonstrated that cutaneous Leishmaniasis is an under recognized presentation of Leishmaniasis with significant cases noted in individuals inhabiting in the Terai belt as well as hilly region $[5,6]$.

Malaria and visceral Leishmaniasis co-infection are noted in certain African studies constituting almost 4.1\% in endemic regions. There is dearth of literature of cases of co-infection in Nepal [2]. Certain studies have demonstrated co-infection prevalence rate ranging from 3.8 to $60.8 \%$ [7]. Our case was a child who was treated locally for on and off fever and demonstrated co-infection for P. vivax and Leishmaniasis. In our case, splenomegaly was present with no evidence of infarction on ultrasound. Few cases of co-infection have been reported with splenic infarction [8]. Our case is unique with presence of pancytopenia which although sometimes noted with $P$. falciparum infection is a rare presentation of $P$. vivax infection. Moreover, treatment with chloroquine is often not effective requiring other drugs including Artesunate [9]. Since, our patient hailed from choloroquine sensitive areas, oral chloroquine was used a first line antimalarial drug along with injectable liposomal amphotericin B. 
Our case has highlighted potential areas of concern in endemic regions for malaria and Leishmaniasis. Firstly, in a resource limited settings as ours, vector control programs should be in an integrated and coordinated manner addressing endemic diseases as a whole and not indivualised; high risk areas and population groups should be identified beforehand. Routine screening for possible co-infection should be performed as delay in diagnosis and treatment results in significant morbidity and mortality. Besides, potential treatment failure and adverse reactions while managing such cases should be understood and planned accordingly. A high index of suspicion for a possibility of a co-infection is to be made when individuals hailing from endemic regions present with fever.

\section{Abbreviations}

LD: Leishmania donovani; P. vivax: Plasmodium vivax; RBC: Red blood cell count; rK39: Ribosomal kininogen; WBC: White blood cell count

\section{Acknowledgments}

Not applicable.

\section{Authors' contributions}

PGG and PG designed the study and created the final draft of the manuscript. PGG and PG collected data relating to the Case Report. PGG, PG, $\mathrm{JA}$ and $\mathrm{AC}$ conducted the study. All authors read and approved the final manuscript.

\section{Funding}

No any funding was obtained for this study.

\section{Availability of data and materials}

The datasets used and/or analyzed during the current study are available from the corresponding author on reasonable request.

\section{Ethics approval and consent to participate}

This study was approved by the ethics committee of Nepalgunj Medical College and Teaching hospital.

\section{Consent for publication}

Written informed consent for publication of clinical details and/or clinical images was obtained from the patient's parents.

\section{Competing interests}

The authors declare that they have no competing interests.

\section{Author details}

'Department of Pathology, Nepalgunj Medical College and Teaching Hospital, Kohalpur, Banke 21904, Nepal. ²Department of Radiology, Nepalgunj Medical College and Teaching Hospital, Banke 21904, Banke, Nepal. ${ }^{3}$ Department of Pediatrics, Nepalgunj Medical College and Teaching Hospital, Banke 21904, Banke, Nepal. ${ }^{4}$ Department of Emergency, Bheri Provincial Hospital, Banke, Banke, Nepal.

Received: 18 January 2019 Accepted: 13 September 2019 Published online: 15 October 2019

\section{References}

1. Shrestha M, Pandey BD, Maharjan J, Dumre SP, Tiwari PN, Manandhar KD, et al. Visceral leishmaniasis from a non-endemic Himalayan region of Nepal. Parasitol Res. 2018;117(7):2323-6.

2. Ferede G, Diro E, Getie S, Getnet G, Takele Y, Amsalu A, et al. Visceral Leishmaniasis-malaria Coinfection and their associated factors in patients attending Metema hospital, Northwest Ethiopia: Suggestion for Integrated Vector Management. Malar Res Treat. 2017;2017:6816913.
3. Rijal KR, Adhikari B, Ghimire P, Banjara MR, Hanboonkunupakarn B, Imwong $\mathrm{M}$, et al. Epidemiology of plasmodium vivax malaria infection in Nepal. Am J Trop Med Hyg. 2018;99(3):680-7.

4. Banjara MR, Kroeger A, Huda MM, Kumar V, Gurung CK, Das ML, et al. Feasibility of a combined camp approach for vector control together with active case detection of visceral leishmaniasis, post kala-azar dermal leishmaniasis, tuberculosis, leprosy and malaria in Bangladesh, India and Nepal: an exploratory study. Trans R Soc Trop Med Hyg. 2015;109(6):408-15.

5. Pandey BD, Pun SB, Kaneko O, Pandey K, Hirayama K. Case report: expansion of visceral leishmaniasis to the western hilly part of Nepal. Am J Trop Med Hyg. 2011;84(1):107-8.

6. Gautam Ghimire P, Shrestha R, Pandey S, Pokhrel K, Pande R. Cutaneous Leishmaniasis: a neglected tropical vector borne disease in Midwestern region of Nepal. Nepal J Dermatol Venereol Leprol. 2018;16(1):41-4.

7. van den Bogaart E, Berkhout MM, Nour AB, Mens PF, Talha AB, Adams ER, et al. Concomitant malaria among visceral leishmaniasis in-patients from Gedarif and Sennar States, Sudan: a retrospective case-control study. BMC Public Health. 2013;13:332.

8. Singh BJ, Kumar A. Splenic infarctions in mixed infection with kala azar and falciparum malaria. J Assoc Physicians India. 1991;39(3):293.

9. Albaker W. Acute plasmodium vivax malaria presenting with pancytopenia secondary to hemophagocytic syndrome: case report and literature review. J Fam Community Med. 2009;16(2):71-3.

\section{Publisher's Note}

Springer Nature remains neutral with regard to jurisdictional claims in published maps and institutional affiliations.

Ready to submit your research? Choose BMC and benefit from

- fast, convenient online submission

- thorough peer review by experienced researchers in your field

- rapid publication on acceptance

- support for research data, including large and complex data types

- gold Open Access which fosters wider collaboration and increased citations

- maximum visibility for your research: over $100 \mathrm{M}$ website views per year

At BMC, research is always in progress.

Learn more biomedcentral.com/submissions 